\title{
Heat-retainer hearth identification as a component of archaeological survey in western NSW, Australia
}

\author{
Patricia C. Fanning ${ }^{1}$ \\ Simon J. Holdaway ${ }^{2}$ \\ Rebecca S. Phillipps ${ }^{2}$
}

\author{
1 Graduate School of the Environment, \\ Macquarie University, \\ NSW 2109, Australia \\ 2Department of Anthropology, \\ University of Auckland, Private Bag 92109, \\ Auckland, New Zealand
}

\begin{abstract}
Concentrations of heat-fractured rock are common in some areas of western New South Wales, Australia, and are frequently identified during archaeological surveys as the eroded remains of heat-retainer hearths, a type of earth oven used in the past by Aboriginal people to cook food. However, it can be difficult to consistently identify these features since heat-fractured rocks, like other clasts lying on the surface, can be dispersed or concentrated by a variety of geomorphic processes. In this paper, we describe a method we have developed for hearth identification and description to aid the consistent recording of these features. We recommend the use of a fluxgate gradiometer as a tool to verify that concentrations of heat-fractured rock are indeed the eroded remains of heat-retainer hearths. Using a gradiometer reduces observer variability and ensures that we are not overestimating the number of hearths present by including naturally occurring groups of stones not related to hearth activity. Adoption by others of a common method of hearth identification and classification would provide some degree of standardisation that will aid understanding of the patterns of Aboriginal occupation in the past.
\end{abstract}

Keywords: geoarchaeology; Australia; Aboriginal; hearth; fluxgate gradiometer 


\section{Introduction}

Surface artefact scatters in western New South Wales (NSW) (Figure 1) are almost always associated with the remains of one or more heat-retainer hearths, or earth ovens, used in the past by Aboriginal people to cook food (Allen 1972:280-1; Peake-Jones 1988). Hearths are an important part of the archaeological record in this region because they are an easily recognisable indicator of past Aboriginal occupation. For archaeologists, they provide a means for developing a chronology of Aboriginal occupation using radiocarbon determinations from charcoal preserved beneath the fire-cracked rock (e.g. Holdaway et al. 2002, 2005a), and potentially through optically stimulated luminescence of the stone heat-retainers (Rhodes et al., this volume).

Originally, these hearths were constructed by excavating a depression that formed the body of the oven into which stones and then food items could be placed for cooking. Abandonment would in many cases lead to the infilling of the depression, thereby burying and preserving the remains of the hearth. Once buried, hearths were probably difficult to identify even by the people who made them, and our research has thus far shown little evidence of extensive re-use, at the level of precision currently attained by conventional radiocarbon age determinations. However, like the stone artefacts with which they are commonly associated, their visibility in western NSW today is a consequence of erosion processes that are exposing them at the surface, where we can see them, and at the same time causing their destruction. Hearths are no longer being produced, therefore the population is finite and, as a consequence of erosion, declining year by year. It is therefore important for both cultural and scientific reasons to document the record of Aboriginal occupation that they represent before they disappear. In this paper, we describe techniques developed to identify, classify and record the remains of heat-retainer hearths in far north-western NSW. We focus on the use of the magnetic properties of the fire-cracked rock to provide an objective test of the degree of preservation of the hearths and their charcoal. The techniques of hearth identification and classification we describe are a key component of survey methods we have developed to understand the Aboriginal archaeological record in its contemporary landscape setting.

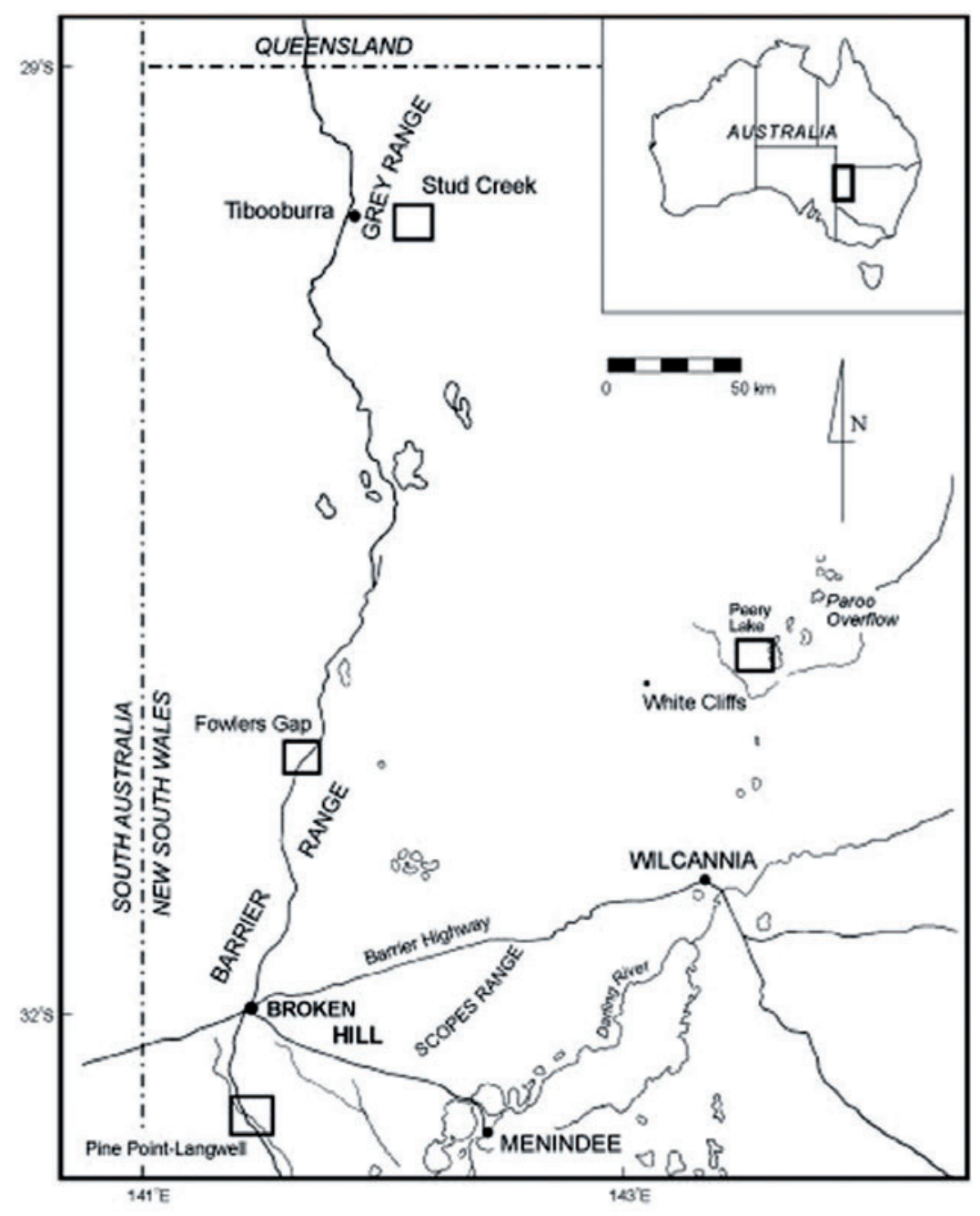

Figure 1. Map of western NSW showing locations mentioned in the text. 


\section{Problems with hearth identification}

Heat-retainer hearth remains are commonly identified during surface archaeological surveys in western NSW. They are most often found along the banks of creeks, on lake margins, in sand dunes, and exposed on scalds and claypans. At times, hearths may appear in dense concentrations. For example, a recent survey of part of the valley floor of Campbells Creek at Poolamacca, about $80 \mathrm{~km}$ north of Broken Hill (Figure 1), revealed at least 220 hearths in an area a little over $500 \mathrm{~m}$ in length by $200 \mathrm{~m}$ wide (Holdaway et al. 2005b), an average density of one hearth to every $450 \mathrm{~m} 2$. This situation is not unusual: a similarly dense distribution was located in 2002 adjacent to Peery Creek in a section of the Paroo Darling National Park (Holdaway et al. 2006). However, there are other parts of the contemporary landscape where heatretainer hearth remains are either absent or at least not visible on the surface.

Because the density of hearths has something to say about the intensity with which Aboriginal people used different parts of the landscape in the past - the more so since many hearths can provide age estimates, something that is largely impossible when analyzing stone artefacts - it is particularly important that hearth remains are unambiguously identified. Comparing the density of hearths from different locations assumes two kinds of comparability: hearths are equally visible and hearths are equally definable.

The first requires an equal state of erosion such that hearths are exposed to an equal degree. This, however, is obviously not the case, since the contemporary landscape is a mosaic of erosional and depositional surfaces. To date, our approach to this problem has been to map land surfaces in great detail, separating eroded surfaces from those still covered with surface sediment, vegetation, etc. (Fanning and Holdaway 2004). Depositional areas may conceal hearths, but we have not yet attempted a systematic survey of these areas to locate buried hearths, for two reasons. First, test pitting, while potentially applicable, requires very close spacing to identify relatively small features across large areas (Wobst 1983), and is therefore very labour intensive. Second, large scale surface disturbance is increasingly out of favour with both Aboriginal people and heritage managers. Geophysical survey, as discussed below, offers a non-destructive alternative to test pitting but we have not so far explored this option for identifying buried hearths.

The second issue, the ability to determine when a hearth is indeed the remains of a past cooking fire, and not simply a pile of naturally occurring rocks or a low density scatter of fire-cracked rocks, requires consistency in field recording. Up to now, our approach has been to identify concentrations of heat-fractured rock and label these as hearths. Heat-cracked rock has a number of characteristics that permit rapid identification, for example 'pot-lids' may be shed during rapid heating (Purdy 1975 in Hiscock 1985), and crazing patterns (a grid of cracks on the rock surface caused by rapid heating and cooling - Hiscock 1997) may be apparent. Identification is easiest when the heat-fractured stones are concentrated together but becomes progressively harder as erosion disperses the fragments. Identification also depends on the nature of the land surface: hearth remains on surfaces covered with a gravel lag, for instance, can be almost impossible to identify. In addition, erosion may lead to the combining of stones from a number of hearths, the individual identity of which may be very difficult to define.

\section{The Western NSW Archaeology Program hearth survey protocol}

In response to the variable state of hearth preservation in western NSW, we developed a hearth survey protocol based on a system initiated by Dan Witter, formerly a NSW National Parks and Wildlife Service archaeologist for western NSW. The survey strategy involves an intensive pedestrian survey with the aim of identifying potential hearths and marking each with a coloured flag (Figure 2). Identification at this stage is based on the presence of any concentration of heat-fractured stones. 
The hearth recording team then re-visits each of the marked concentrations and attaches a tag stamped with a number against which all the attributes of each putative hearth are subsequently entered into a database. Attributes recorded for each hearth include:

1. location - AMG co-ordinates determined using differential GPS;

2. dimensions - maximum length and perpendicular width of the cluster of hearth stones, measured with a steel tape;

3. orientation - azimuth of the maximum dimension;

4. number and lithology of hearth stones;

5. presence of any visible charcoal;

6. condition of the hearth (see below).

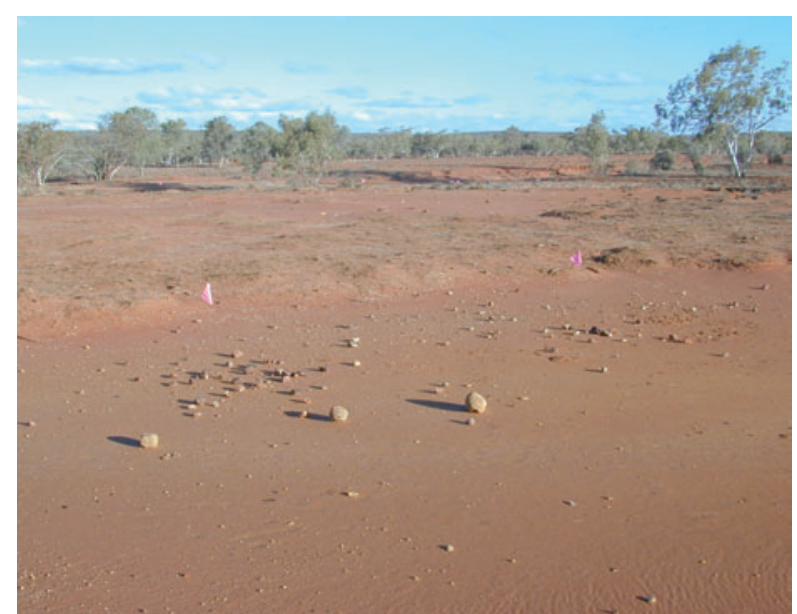

Figure 2. The remains of heat retainer hearths on an eroded surface in Paroo Darling National Park in western NSW. Hearths identified in the initial intensive pedestrian survey are marked with a coloured surveyor's flag (pink in this image).

A digital image is also taken. Several of these attributes are necessary for entry into the NSW Aboriginal Heritage Information Management System (colloquially, the 'site register'), as hearths are classified as 'sites' under that system (NSW Department of Environment and Conservation 2006).

The condition of each hearth is determined from visual assessment of the degree of disturbance by processes including erosion or bioturbation. Six categories are defined (Figure 3, a to f): buried, partially exposed, intact, disturbed, scattered, remnant. Use of the term 'buried' to describe a category of hearth disturbance may seem inconsistent since this is a classification of the condition of hearths exposed at the surface. However, this term is useful for describing hearths that remain largely buried with only the tips of the fire-cracked rock poking above the surface (Figure 3a).

Partially exposed hearths are relatively common in our study locations. This term is used to describe hearths where a portion of the dense cluster of hearth stones is exposed along an erosion escarpment (Figure 3b), but the bulk of the hearth remains buried. Intact hearths are those where erosion has completely exposed the dense cluster of fire-cracked rock but it has not been dispersed (Figure 3c).

The next three categories - disturbed, scattered and remnant - refer to hearths displaying increasing amounts of disturbance of the heat retainers. Disturbed hearths (Figure 3d) still retain a roughly circular form although stones are more dispersed in comparison to intact hearths. Scattered hearths (Figure 3e) have lost this circular form and the heat retainers are unevenly spread across the surface, with no clear focal point. Remnant hearths are at the last identifiable end point of the disturbance continuum. These hearths retain a circular structure (Figure 3f) but the hearth stones form an open ring or 'halo' with no stones present at the centre. They are often characterised by relief inversion, with the former centre of the hearth pit now forming the apex of a shallow cone with the hearthstones completely dispersed around the edges.

\section{Applying the hearth condition classification}

A recent survey of Rutherfords Creek in the Peery Lake section of Paroo Darling National Park (Figure 1) identified 416 potential hearths in an area of approximately $2.5 \mathrm{~km}^{2}$. Around half are relatively undisturbed (Table 1), being categorised as buried, partially exposed or intact using the classification described above. The others are damaged, having been classified as either disturbed, scattered or remnant. The three hearths identified as buried are likely to be an underestimate of the true number of buried hearths since a large proportion of the valley floor of Rutherfords Creek is currently buried by modern sediments. 

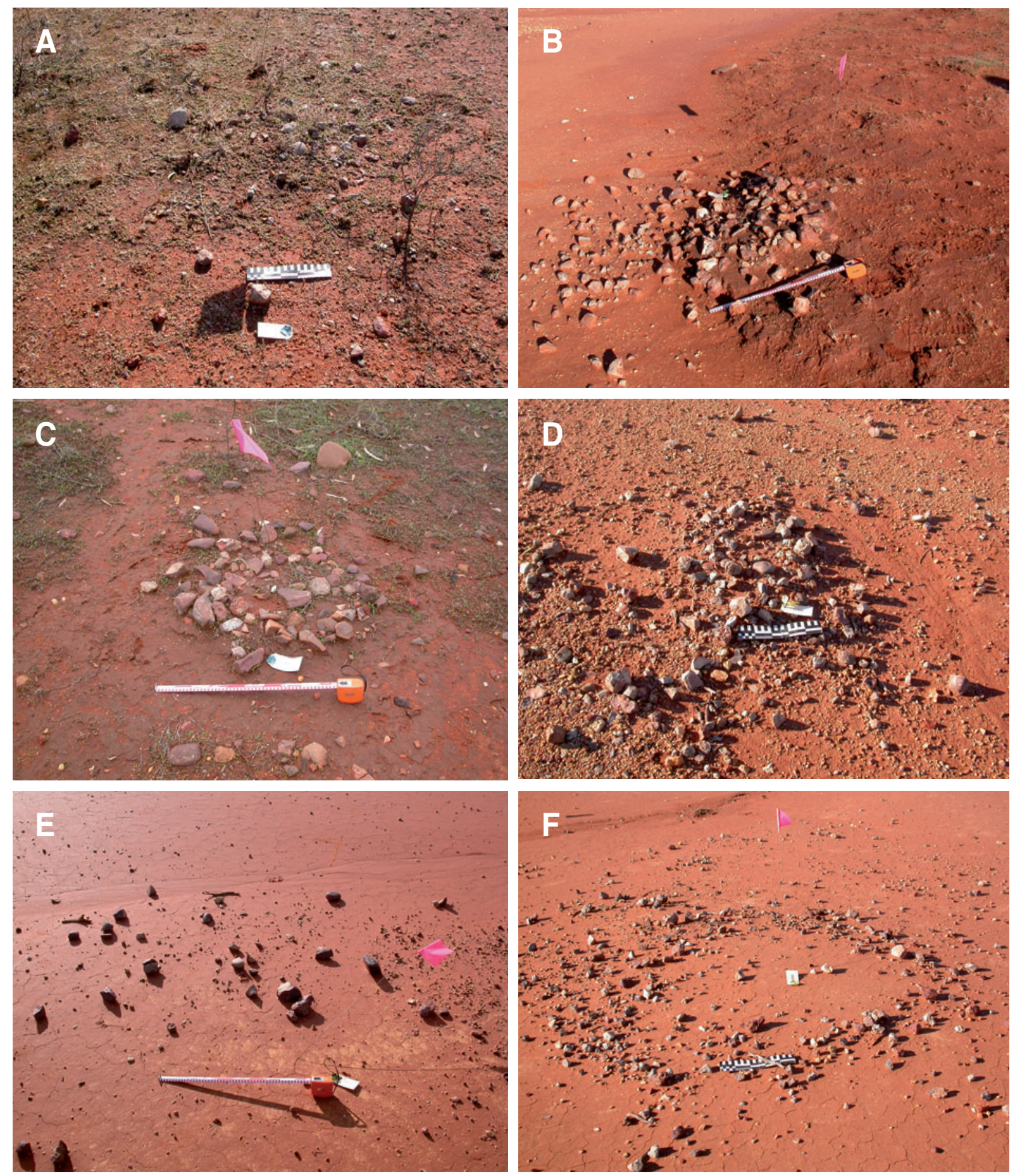

Figure 3. Images of heat retainer hearths from western NSW that illustrate the six categories of hearth condition recognised in the survey protocol:
a. buried
b. partially exposed
c. intact
d. disturbed
e. scattered
f. remnant 


\begin{tabular}{|c|c|c|c|c|c|c|}
\hline Hearth Condition & Number & $\begin{array}{l}\text { Proportion } \\
(\%)\end{array}$ & $\begin{array}{l}\text { Pearson } \\
\text { Correlation } \\
\text { Coefficient }\end{array}$ & $\mathbf{P}$ & $\begin{array}{l}\text { Spearman } \\
\text { Rank Order } \\
\text { Correlation } \\
\text { Coefficient }\end{array}$ & $\mathbf{P}$ \\
\hline Buried & 3 & 1 & $\mathrm{n} / \mathrm{a}$ & $\mathrm{n} / \mathrm{a}$ & $\mathrm{n} / \mathrm{a}$ & $\mathrm{n} / \mathrm{a}$ \\
\hline Partially exposed & 179 & 43 & 0.4 & $<0.01$ & 0.17 & 0.03 \\
\hline Intact & 56 & 13 & 0.35 & 0.01 & 0.42 & $<0.01$ \\
\hline Disturbed & 96 & 23 & 0.23 & 0.03 & 0.24 & 0.2 \\
\hline Scattered & 62 & 15 & 0.38 & 0.77 & 0.54 & 0.68 \\
\hline Remnant & 20 & 5 & 0.27 & 0.24 & 0.48 & 0.03 \\
\hline Total & 416 & & & & & \\
\hline
\end{tabular}

Table 1. Hearth types recorded along a section of the valley floor of Rutherfords Creek in Paroo Darling National Park in western NSW. Pearson and Spearman correlation coefficients are parametric and non-parametric measures of the strength of the relationships between the gradiometer reading and number of hearth stones for identified hearths of each condition type. Significant results are indicated by italics.

The proportion of the Rutherfords Creek valley floor that is eroded can be used to estimate the true density of hearths, including those still buried, using two techniques. First, we use digital aerial photographs and image analysis software to estimate the area of the valley floor covered by scalds. We also measure the length and breadth of scalds as part of our artefact survey strategy, and thus can calculate the area of exposed surfaces.

However, the second part of the calculation for hearth density in Rutherfords Creek requires that the count of hearths is accurate. Here we face the problem of inconsistency in hearth identification. Are the hearths we have categorised as disturbed, scattered and remnant actually hearths, or are they simply concentrations of heat-fractured stones grouped together as the result of natural processes? A more objective means of identifying hearth remains is required to overcome this problem.

\section{Gradiometer survey as an objective method of hearth identification}

Our solution was to employ a fluxgate gradiometer to provide a more objective measure of the potential for the stones to have been heated in situ, from which we could be more confident of positive hearth identification. The gradiometer works by recording minute distortions in the earth's magnetic field at particular locations. We used a Geoscan Research Fluxgate Gradiometer FM36 (Figure 4) to search for near-surface magnetic anomalies. The gradiometer returns positive and negative readings in nanoTeslas (nT), with a background value of around zero. In accordance with the discussion in Jones and Munson (2005), it is likely that the readings taken at Rutherfords Creek derive from two sources. First, heating of rocks and soil in hearths can increase the magnetic susceptibility of minerals leading to the preferential flow of a geomagnetic field through these minerals and, as a consequence, locally higher field strength. In addition, if minerals are heated above a critical temperature (the Curie temperature, $120^{\circ} \mathrm{C}-675^{\circ} \mathrm{C}$ ) they will acquire permanent magnetism (termed 'thermo-remnant magnetism' or TRM). The gradiometer measures both sources.

Unlike conventional approaches, where gradiometer measurements are taken in a systematic grid across a surface, we were not concerned here with identifying buried hearths. Instead, to further investigate hearths identified during our initial pedestrian survey, we employed the gradiometer in 'survey' mode (Clark 2000). At each location, the gradiometer was zeroed against a background surface that lacked heat-fractured stones. Readings were taken along a transect aligned north-south across a potential hearth, the operator noting the maximum reading (either positive or negative) along the transect. 


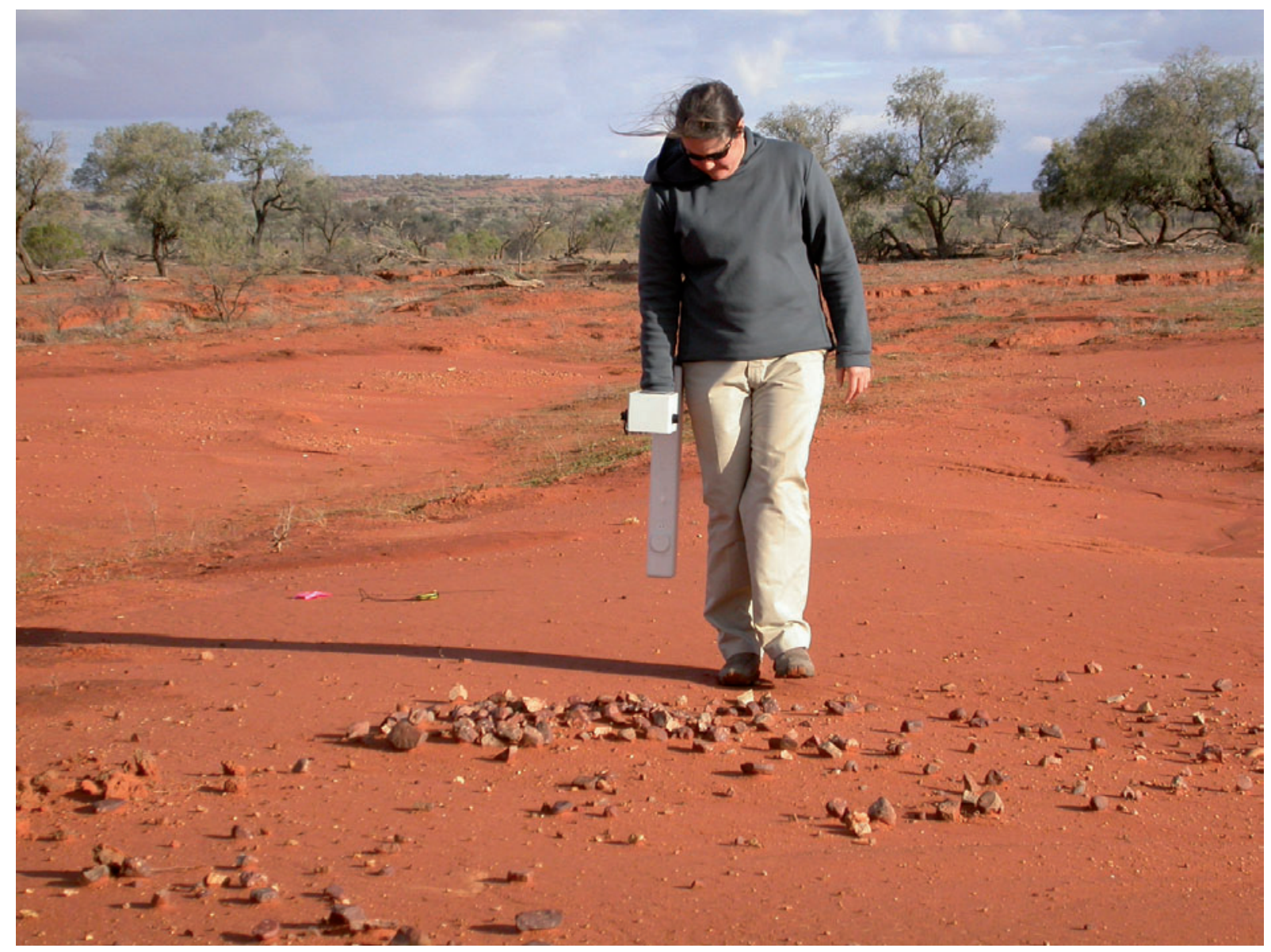

Figure 4. Rebecca Phillipps calibrates the Geoscan Research Fluxgate Gradiometer FM36 used in this survey.

Figures 5a to 5e illustrate the differences between the hearth reading and the background reading for hearths in the different categories described above. Buried hearths are not included in the analysis as there were too few readings to graph the results. For both partially exposed and intact hearths, the differences are quite large, up to $+65 \mathrm{nT}$ and $-95 \mathrm{nT}$ in some cases. But for disturbed, scattered and remnant hearths the differences between the background and the hearth readings are much smaller, as we would expect if the heat-fractured rocks were in low concentrations.

We tested the relationship between the number of hearth stones and the magnitude of the gradiometer readings using both parametric and non-parametric tests. There is a significant correlation in both cases (Table 1), suggesting that TRM is contributing significantly to the gradiometer readings over the hearths. This relationship is clearest for partially exposed, intact and disturbed hearths. For the scattered and remnant categories, the statistical tests indicate that there is only a weak relationship between the numbers of hearth stones and the gradiometer readings, which would be expected given the higher degree of dispersion of heat-fractured rock for the hearths in these two categories. The significant result for the Spearman rank correlation test on the remnant hearths (Table 1) is probably because the 20 hearths of this type recorded were those with the highest density of hearth stones. 
a. Partial Exposure

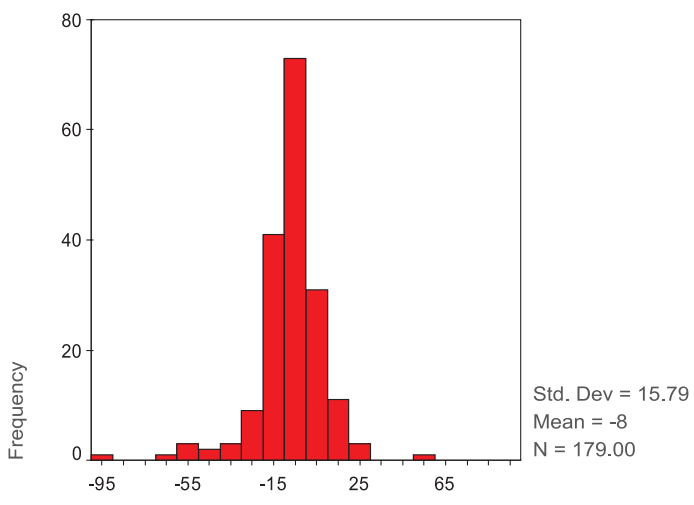

Difference to background $\mathrm{nT}$

C. Disturbed

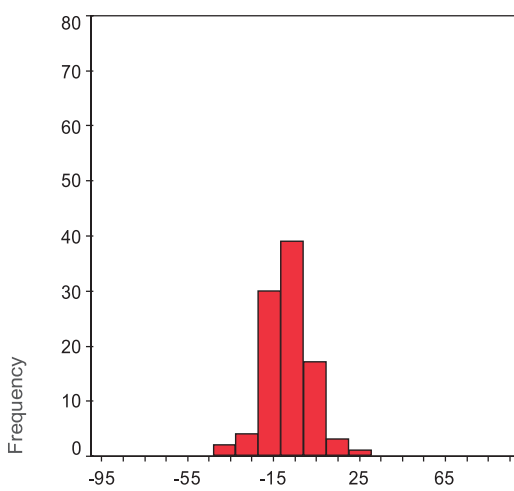

Difference to background $\mathrm{nT}$

e. Remnant

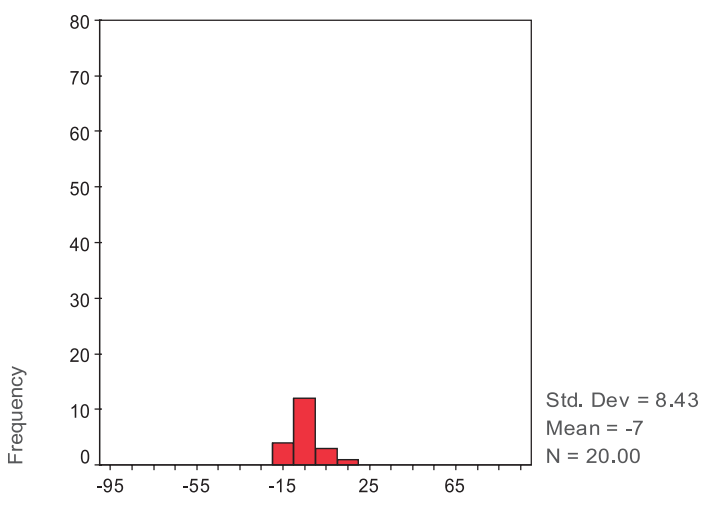

Difference to background $\mathrm{nT}$ b. Intact

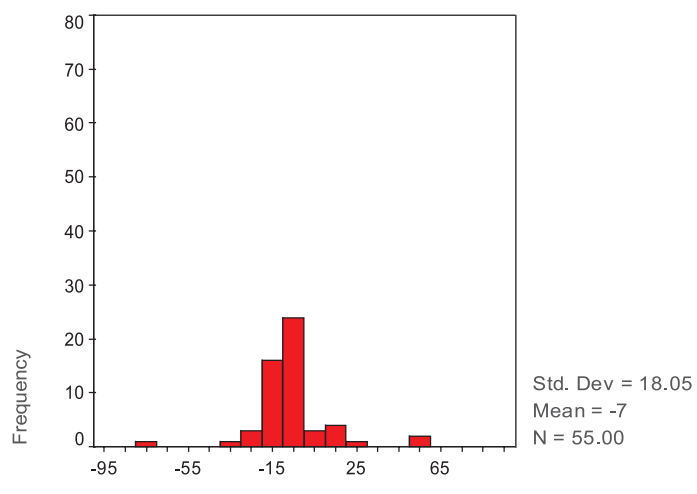

Difference to background $\mathrm{nT}$

d. Scattered

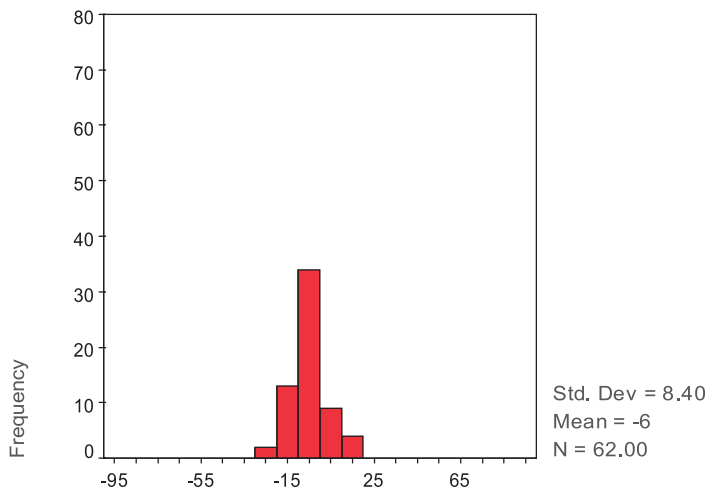

Difference to background $\mathrm{nT}$

Figure 5. Histograms showing the differences in the TRM between the hearths and the background for each of the hearth condition categories identified in the survey:

a. partially exposed; $\quad$ b. intact; c. disturbed; d. scattered; e. remnant. 


\section{Discussion}

The trial to test the effectiveness of using a gradiometer survey to identify fire-affected rock, described above, produced promising results. Those hearths with the densest concentration of heat-fractured stones produced magnetic readings exhibiting the largest differences from the background magnetism. The correlation between the number of hearth stones and the strength of the difference to background for the different hearth types suggests that much of the signal read by the gradiometer relates to TRM. If so, then a case can be made that the gradiometer is an effective tool for objectively identifying hearths in a continuum that runs from the 'intact' through to 'remnant' categories (Table 1).

The primary issue here is not just accurately identifying former hearths. It is more about objectively determining a point in the progressive destruction of hearths by erosion at which the location where the hearth once existed can no longer be defined. The hearths that are now categorised as remnant were once buried. As erosion progresses, defining the number and precise location of hearths becomes more difficult, and calculating the original density of hearths on a valley floor is problematic.

Our experiments show that use of a gradiometer in survey mode provides an objective measure of hearth 'intactness' that can be used with the condition classification described above. Based on our experience at Rutherfords Creek, if the reading over a collection of heat-fractured stones varies very little from background, i.e. within $\pm 5 \mathrm{nT}$, then it is excluded from further survey. In imposing these somewhat arbitrary threshold values we may well be excluding some clusters that once were hearths, but we are certainly not including those that were not. Hence, we can be sure that we are not overestimating the number of hearths present in this location by including such phenomena as naturally occurring groups of stones not related to hearth activity. Use of the gradiometer also provides us with an objective measure that allows us to take account of both inter- and intra-observer variability, a source of measurement variance that previously has proved significant in our analyses of stone artefacts (Gnaden and Holdaway 2000).

Use of the gradiometer at Rutherfords Creek was a pilot study and we plan to expand its use in the future. In particular, we need to take measurements on stone clusters that we know were never part of a hearth, to better understand how values from these features compare to our intact hearth category. We also need to undertake controlled experiments by creating our own hearths to determine the absolute effects on the gradiometer readings of the degree of stone scatter, and the effects of different lithologies. Controlled experiments might also allow us to determine whether or not hearth reuse can be detected.

\section{Conclusions}

The eroded remains of heat-retainer hearths in western NSW are an important aspect of the archaeological record because they are highly visible, are easy to interpret and can be dated. Unfortunately their visibility is a result of processes that are also leading to their destruction. Erosion and bioturbation are progressively leading to partial exposure then destruction of the original hearth, as the heat retainers are scattered. Eventually the lack of integrity is such that hearth identification becomes problematic. Hearths are protected by heritage conservation legislation, but this only ensures protection against destruction through development or deliberate vandalism, not 'natural' erosion or damage by domestic stock. Hearths are a diminishing resource and our research suggests that archaeologists have a limited time to study this resource before it is gone forever. Our hearth classification scheme, if universally adopted, provides standardisation of hearth identification that will allow comparison between separate archaeological surveys, and monitoring of changes in hearth condition over time.

The techniques described here provide an objective means for identifying hearths based on combining a classification of condition and use of a fluxgate gradiometer, and therefore provide a way to estimate the number and condition of the hearths that remain in particular locations. Results suggest that 
differences in the gradiometer readings relative to local background are largely due to remnant thermomagnetism in the heat retainers. Those hearths with high numbers of heat-fractured stones concentrated in a small area provide the largest deviations from background. Those concentrations of hearth stones that give values at or below $\pm 5 \mathrm{nT}$ should probably not be considered hearths.

When combined with a detailed assessment of stone artefacts (e.g. Holdaway et al. 2004) and a program of obtaining age estimates for the hearths (e.g. Holdaway et al. 2005a; Fanning et al. 2008), study of heat-retainer hearths offers the opportunity to detail both the chronology and intensity of Aboriginal use of place in the past.

\section{Acknowledgements}

This project was funded by an ARC Discovery Grant to Fanning, Holdaway and Rhodes. We thank the Wilcannia Local Aboriginal Lands Council and the Wilcannia Community Working Party and the people they represent for permission to work on their traditional lands and to collect samples of charcoal from the hearths. We particularly thank Murray Butcher, Warlpa Thompson and Bilyara Bates and students from the University of Auckland for their help with fieldwork. We also thank Badger Bates and Sarah Martin for their help and support. The NSW Department of Environment and Climate Change gave permission for the research to be conducted on Paroo Darling National Park, and we are grateful to departmental officers for their assistance, particularly Phil Purcell and Christian Hampson. Thanks also to Peter Hiscock for helpful comments on the submitted paper. 


\section{References}

Allen, H. 1972. Where the crow flies backwards: Man and land in the Darling Basin. Unpublished PhD thesis. Canberra: Department of Prehistory, Research School of Pacific Studies, Australian National University.

Clark, A. 2000. Seeing beneath the soil: Prospecting methods in archaeology. New York: Routledge.

Fanning, P. C. and S. J. Holdaway. 2004. Artifact visibility at open sites in western New South Wales. Australia. Journal of Field Archaeology 29(3-4):255-271.

Fanning. P. C., S. J. Holdaway and E. J. Rhodes. 2008. A new geoarchaeology of Aboriginal artefact deposits in western NSW, Australia: Establishing spatial and temporal geomorphic controls on the surface archaeological record. Geomorphology 101:524-532.

Gnaden, G. and S. J. Holdaway. 2000. Understanding observer variation when recording stone artifacts. American Antiquity 65:739-748.

Hiscock P, 1985. The need for a taphonomic perspective in stone artefact analysis. Queensland Archaeological Research 2:82-95.

Hiscock, P. 1997. Taphonomy of artefacts. http://arts.anu.edu.au/arcworld/resources/intro/tapho.htm

Holdaway, S. J., P. C. Fanning, D. Witter, M. Jones, G. Nicholls and J. Shiner. 2002. Variability in the chronology of Late Holocene Aboriginal occupation on the arid margin of southeastern Australia. Journal of Archaeological Science 29:351-363.

Holdaway, S. J., P. C. Fanning and J. Shiner. 2005a. Absence of evidence or evidence of absence? Understanding the chronology of Indigenous occupation of western New South Wales, Australia. Archaeology in Oceania 40:33-49

Holdaway, S. J., P. C. Fanning, E. J. Rhodes and Broken Hill Local Aboriginal Lands Council. 2005b. A geoarchaeological and geochronological assessment of the surface archaeology of the Campbells Creek area, 'Poolamacca' Station, western NSW. Unpublished report for NSW Department of Environment and Conservation.

Holdaway, S. J., P. C. Fanning and J. Shiner. 2006. Geoarchaeological investigation of Aboriginal landscape occupation in Paroo Darling National Park, Western NSW, Australia. Research in Anthropology and Linguistics $-e 1$. University of Auckland: Department of Anthropology.

Holdaway, S. J., J. Shiner and P. C. Fanning. 2004. Hunter-gatherers and the archaeology of the long term: An analysis of surface stone artefact scatters from Sturt National Park, New South Wales, Australia. Asian Perspectives 43(1):34-72.

Jones, G. and G. Munson. 2005. Geophysical survey as an approach to the ephemeral campsite problem: Case studies from the Northern Plains. Plains Anthropologist 50:193-224.

NSW Department of Environment and Conservation. 2006. Aboriginal Heritage Management System. http://www.nationalparks.nsw.gov.au/npws.nsf/Content/Aboriginal+Heritage+Information+ Management+System. Accessed 26th May 2006.

Peake-Jones, K. 1988. To the desert with Sturt: A diary of the 1844 expedition. Adelaide: South Australian Government Printer.

Rhodes, E. J., P. C. Fanning, S. J. Holdaway and C. Bolton. 2008. Archaeological surfaces in western NSW: Stratigraphic contexts and preliminary OSL dating of hearths. In A. Fairbairn and S. O'Connor (eds), Proceedings of the 8th Australasian Archaeometry Conference, December 2005, Canberra.

Wobst, M. 1983. We can't see the forest for the trees: Sampling and the shapes of archaeological distributions. In J. Moore and A. Keene (eds), Archaeological hammers and theories, pp 37-85. New York: Academic Press. 